\title{
Driving-forces for Greenland Offshore Groundfish Assemblages: Interplay of Climate, Ocean Productivity and Fisheries
}

\author{
Heino O. Fock \\ Institute of Sea Fisheries, Palmaille 9, D 22767 Hamburg, Germany \\ Email: heino.fock@ish.bfa-fisch.de
}

Fock, H. 2007. Driving-forces for Greenland offshore groundfish assemblages: interplay of climate, ocean productivity and fisheries. J. Northw. Atl. Fish. Sci., 39: 103-118. doi:10.2960/J.v39.m588

\begin{abstract}
Principal component analysis of German survey data from 1981 to 2006 yielded four main trend components accounting for $60 \%$ of variance of the demersal fish assemblage on the Greenland shelf. The leading principal component (prin1) accounted for $22.5 \%$ of total variance of abundance and was positively correlated with deep-sea and golden redfish $>17 \mathrm{~cm}$ (Sebastes mentella and $S$. marinus, respectively). Prin 2 accounted for $16.7 \%$ of total variance of abundance and was correlated to juvenile redfish $<17 \mathrm{~cm}$. Prin 3 and prin 4 accounted for $12.9 \%$ and $7.5 \%$ of total variance, respectively. American plaice (Hippoglossoides platessoides) was attributed to prin3. Atlantic cod (Gadus morhua) was almost equally assigned to prin3 and prin4. Prin1 and prin4 were significantly correlated with air temperature anomalies from Nuuk $(\mathrm{p}<0.01)$, representing the climate effect on the demersal assemblage. Prin2 and prin3 were significantly correlated with the July-August phytoplankton colour index for East Greenland representing ocean productivity and fishing mortality from cod VPA analysis, the latter indicating fishing pressure effects on the ecosystem. About $30 \%$ of total variance can be explained by climate. For East Greenland, strong bottom-up forcing (climate, productivity) and effects of fisheries were identified, whereas for West Greenland both bottom-up (climate) and top-down forcing (community interactions) were effective. With respect to Atlantic cod, fisheries in the case of prin 3 and climate in the case of prin 4 were equally important to explain long-term dynamics.
\end{abstract}

Key words: American plaice, Atlantic cod, Atlantic wolffish, climate, PCA, productivity, redfish

\section{Introduction}

Dynamics of northern temperate demersal fish assemblages are affected by productivity (Beaugrand et al., 2003; Steingrund and Gaard, 2005; Ware and Thomson, 2005), fisheries (e.g. Myers et al., 1997), and climate. Primary effects of either factor at the population level may be either amplified or damped through species interactions on the community level (Walther et al., 2002). Anthropogenic local factors such as fisheries may mask climate effects (Parmesan and Yohe, 2003), which appear on all levels of the marine ecosystem (Francis et al., 1998). On the population level, main response patterns of fishes to increasing sea temperatures are changes in abundance of dominant species (MacDonald et al., 1984; Genner et al., 2004), as well as shifts in latitudinal distributional ranges (e.g. Stebbing et al., 2002; Perry et al., 2005). Further, shifts in inshore-offshore distribu- tions and shifts between nursery and feeding grounds have been attributed to local sea temperature fluctuations (MacDonald et al., 1984; Abookire et al., 2000; Attrill and Power, 2002; Magill and Sayer, 2002).

The Greenland coastal ecosystem is influenced by offshore currents which are strongly affected by climate oscillations at time scales of 40-80 years (Delworth et al., 1997). In East Greenland, the Irminger Current, a warm surface current, parallels the coastal southwardflowing East Greenland Current that carries cold water of low salinity. At West Greenland, both mix into the northward-flowing West Greenland Current with a cold shelf branch and a warmer shelf break branch, the latter appearing at 300-400 $\mathrm{m}$ depth (Stein, 2006a). At West Greenland, pure Irminger water is encountered even deeper, from 400-800 m depth (Stein, 2004), whereas it appears all across the shelf area in East Greenland (Stein, 
MS 2006b). In terms of catch numbers, the Greenland offshore demersal fish assemblage is characterized by dominance of Atlantic cod and redfish with significant differences between West and East Greenland (Rätz, 1999). The dynamics of the West Greenland cod stock reveals that climate may play a major role in changing the ecosystem, concomitant with and as yet not distinguishable from fisheries effects (Brander, 1996; Buch et al., 2003; Hamilton et al., 2003). Greenland cod as a population at the edge of its distribution range and thus far from environmental optimum as are in particular vulnerable to exploitation and environmental change (Brander, 1996). Historically, cod catches were mainly taken in West Greenland waters, only after 1980 cod catches off East Greenland also increased. After the collapse of cod fisheries in 1992, Greenland fisheries started to target shrimp (Hamilton et al., 2003). In 2003, signs of cod stock recovery became evident (ICES, MS 2006).

Only few community analyses of marine fish assemblages have been carried out with respect to climate. Therein, community responses have been defined as main trends in community variability, indicated by means of a leading multivariate surrogate, e.g. factor, etc. Correlations of these surrogates with either sea temperature (Genner et al., 2004) or with latitudinal ranges (Poulard and Blanchard, 2005) have been deployed to indicate community climate effects. In the Gulf of Alaska ecosystem, long term changes in the demersal community with respect to cod and shrimp were related to climate fluctuations as indicated by the regional North Pacific Pressure Index (NPPI), with a only modifying effect of fisheries (Anderson and Piatt, 1999; Anderson, 2000). Joint effects of fisheries and climate off Newfoundland have been analysed semi-quantitively with a production model for a single stock, i.e. cod off Newfoundland (Rose, 2004), but no community level analyses have been performed. The goal of the present analysis is to analyse dynamics of the Greenland offshore demersal fish assemblage by means of multivariate descriptors with respect to internal, i.e. top-down (interactions) and external, i.e. bottom-up forcing (climate change, ocean productivity) and fisheries. The analysis is based on German long term groundfish survey data from the Greenland shelf from 1981 to 2006.

\section{Materials and Methods}

\section{Species focus}

The following fish species (or species groups) were identified as important. Atlantic cod (Gadus morhua, hereafter 'cod'), juvenile redfish $<17 \mathrm{~cm}$ (Sebastes spp.), deep-sea redfish $>17 \mathrm{~cm}$ (Sebastes mentella, also known deepwater or beaked redfish), golden redfish $>17$ cm (S. marinus), American plaice (Hippoglossoides platessoides), Atlantic wolfish (Anarhichas lupus), Spotted wolfish (Anarhichas minor) and Starry ray (Amblyraja radiate).

\section{Environmental data}

For East Greenland, the phytoplankton colour index (PCI) data set for region B7 was acquired from SAHFOS (2006) for the period 1982-86 and 1991-2001. No data were available for West Greenland. The colour index is a relative measure of phytoplankton abundance from Continuous Plankton Recorder samples. B7 extends from $59^{\circ} \mathrm{N} 31^{\circ} \mathrm{W}$ to $63^{\circ} \mathrm{N} 43^{\circ} \mathrm{W}$ (Richardson et al., 2006). Yearly summer (Jul-Aug) values were used in this study. A further method to analyse short and noisy time series by means of the principal components of the embedded time series was applied to highlight the main temporal pattern, denoted as PCI composite (Sirabella et al., 2001, and references therein).

Nuuk annual air temperature anomalies (Nuuk ATA) (Buch and Nielsen, MS 2002; M. Stein, pers. comm.) served as proxy for climate change and were applied for both West and East Greenland. For West Greenland, trends of sea surface temperatures and air temperatures were congruent (Buch et al., 2004). In the present data set, Nuuk ATA were strongly correlated with water temperatures at fishing depth during the German autumn surveys $\left(r^{2}=0.54\right.$, corrected for different survey coverage between years (coverage data in Table 1)).

Fisheries data were acquired from ICES working group reports for the period 1981-1995 including cod survey abundance, cod virtual population analysis estimates (VPA), cod fishing mortality $(F)$, cod offshore catches as the main fisheries and inshore effort data derived from cod catches and raw catch-per-unit-effort data. (ICES, MS 1996, MS 2006). In the present study fishing effort is presumed to be representative for West and East Greenland as an overall proxy. It is assumed that inshore effort from the gill and pound net fisheries and offshore effort from trawl fisheries were correlated, since West Greenland cod catches for these two fisheries were significantly correlated $\left(1981-1995 ; r^{2}=0.56\right)$. Recent parallel trends for both inshore and offshore cod stocks further corroborate this approach. In the 1990s, fisheries started to target shrimp and thus cod based effort data cannot be expected to represent offshore fishing effort adequately since then (Maunder et al., 2006).

The abundance index indicator of Myers et al. (1997) was applied to indirectly check for the applicability of the chosen indicators of fishing pressure, i.e. whether there were signs of collapse coinciding with 
signs of fishing effort and mortality. The index was calculated for cod at age 3, when cod recruits to fisheries at West Greenland (Brander, 1996). The abundance index applies regression versus time of the log ratio of VPA abundance-at-age over survey abundance-at-age to indicate changes in recruitment. Negative slopes indicate that VPA-estimates underrate mortality, a numerical pattern that has been identified associated stock collapse (Myers et al., 1997).

\section{Fish assemblage data from the German groundfish survey}

After an initial summer survey in 1981, annual autumn surveys covering the Greenland shelf and continental slope commenced in 1982 (ICES, MS 1996, MS 2006). The survey area was split into seven geographic strata, each subdivided into two depth strata covering the 0-200 m (shallow) and 201-400 m zones (deep). Strata 1-4 refer to West Greenland and strata 5-7 to East Greenland (Fig. 1). In East Greenland, shallow habitats mainly consist of banks emerging from the deeper areas, the shallow-to-deep area ratio in the survey is $<1$. In West Greenland, shallow habitats prevail with a ratio $>1$ (Tables 1 and 2).

Fishing gear was a standardized 140 -feet bottom trawl, its net frame rigged with heavy ground gear because of the rough nature of the fishing grounds. A liner of small mesh $(10 \mathrm{~mm})$ was used inside the cod end. In 1994, smaller Polyvalent doors $\left(4.5 \mathrm{~m}^{2}, 1500 \mathrm{~kg}\right)$ was introduced to reduce net damages due to overspread caused by the bigger doors $\left(6 \mathrm{~m}^{2}, 1700 \mathrm{~kg}\right)$ previously deployed. The constructional width as specified by the manufacturer is $22 \mathrm{~m}$, the vertical net opening being $4 \mathrm{~m}$. Towing time was 30 minutes at a speed of 4.5 knots. Hauls, in which the netting was torn or the trawl snagged after less than 15 minutes, were rejected. Some hauls from the 1987 and 1988 surveys were included although their towing time had been intentionally reduced to 10 minutes due to expected large cod catches based on observations from echo sounder traces. All hauls were standardised to a towing time of 30 minutes.

\section{Community analysis}

The rationale for the present analysis was to seek 'ideal' community descriptors displaying coherent responses at community level rather than to investigate a single stock. Coherent responses may indicate regime shifts (Steele, 1998). This is different from the intention of obtaining a reduced number of significant variables as usually referred to for multivariate analysis. Principal components analysis is suitable for data sets resolved both on spatial and temporal scales (Heyen et al., 1998;

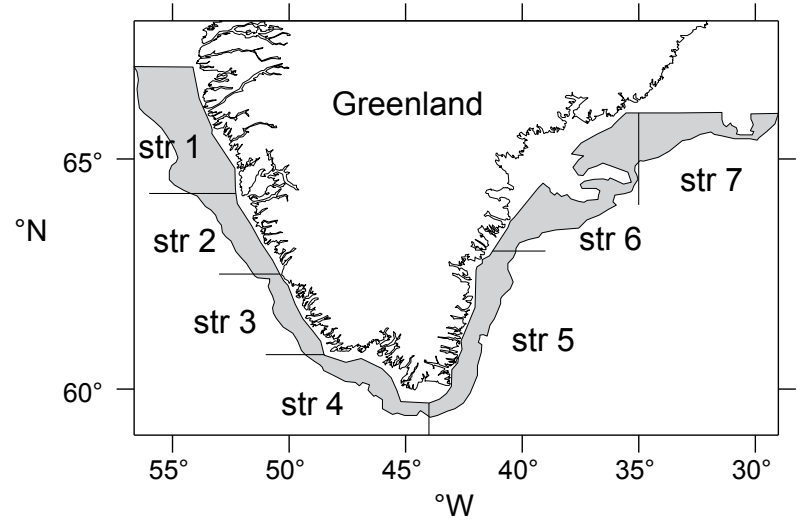

Fig. 1. Survey area of the German Greenland offshore groundfish survey (shaded) and location of strata.

Genner et al., 2004). Principal components (eigenvectors) and sample scores are jointly uncorrelated, i.e. independent of each other.

The underlying equation is

$$
Y=X B+E,
$$

where $Y$ is the matrix of original observations (data by station from 1981 to 2006), $X$ is the matrix of station scores on the principal components, $B$ is the matrix of species loadings to the eigenvectors, and $E$ is the matrix of residuals (Urquhart et al., 1998; SAS, 2003). The scores matrix $X$ is applied to recalculate principal components from the observations matrix $Y$ (PROC SCORE, SAS, 2003). Due to normalization, species loadings to the eigenvectors are equivalent to their correlation coefficients (SAS, 2003; Beaugrand and Ibanez, 2004). As derived from permutations of the original data set $(n=960)$, species loadings, i.e. correlation coefficients $r>|0.3|$ were significant at $p<0.05$.

At the scale of analysis, correction for spatial autocorrelation was not required (Diniz-Filho et al., 2003). Only species present in more than $1 \%$ of the samples were included. Abundance data from 3506 stations were log-transformed and the covariance matrix analysed to account for major quantitative shifts in assemblage composition. Principal components were evaluated by the Kaiser criterion with a minimum eigenvalue $>1$ (Kaiser, 1960), Cattell's rule (Cattell, 1966), and by species loadings. Cattell's rule is a visual technique to retain those principal components that are above the point of inflection in a plot of eigenvalues ordered by diminishing size. Accordingly, Stahel (1999) suggests retaining all principal components that provide reasonable data structure despite the eigenvalue criterion. 
TABLE 1. German autumn survey coverage showing the number of stations undertaken by year and stratum. The strata are divided in to a shallow 0-200 m depth zone (stratum.1) and a deep 201-400 m depth zone (stratum.2). The stratum area $\left(\mathrm{km}^{2}\right)$ and shallow-to-deep ratio (in parentheses) is indicated.

\begin{tabular}{|c|c|c|c|c|c|c|c|c|c|c|c|c|c|c|c|}
\hline Stratum & 1.1 & 1.2 & 2.1 & 2.2 & 3.1 & 3.2 & 4.1 & 4.2 & 5.1 & 5.2 & 6.1 & 6.2 & 7.1 & 7.2 & \\
\hline \multirow{2}{*}{$\begin{array}{l}\text { Area } \\
\text { ratio }\end{array}$} & 6805 & 1881 & 2350 & 1018 & 1938 & 742 & 2568 & 971 & 2468 & 3126 & 1120 & 7795 & 92 & 4589 & \\
\hline & \multicolumn{2}{|c|}{ (3.6) } & \multicolumn{2}{|c|}{$(2.3)$} & \multicolumn{2}{|c|}{ (2.6) } & \multicolumn{2}{|c|}{ (2.6) } & \multicolumn{2}{|c|}{$(0.8)$} & \multicolumn{2}{|c|}{$(0.1)$} & \multicolumn{2}{|c|}{$(0.02)$} & Total \\
\hline 1982 & 20 & 11 & 16 & 7 & 9 & 6 & 13 & 2 & 1 & 10 & 3 & 12 & 1 & 25 & 136 \\
\hline 1983 & 26 & 11 & 25 & 11 & 17 & 5 & 18 & 4 & 3 & 19 & 10 & 36 & 0 & 18 & 203 \\
\hline 1984 & 25 & 13 & 26 & 8 & 19 & 6 & 20 & 4 & 5 & 4 & 2 & 8 & 0 & 5 & 145 \\
\hline 1985 & 10 & 8 & 26 & 10 & 17 & 5 & 21 & 4 & 5 & 21 & 14 & 50 & 0 & 28 & 219 \\
\hline 1986 & 27 & 9 & 21 & 9 & 16 & 7 & 18 & 3 & 3 & 15 & 14 & 37 & 1 & 34 & 214 \\
\hline 1987 & 25 & 11 & 21 & 4 & 18 & 3 & 21 & 3 & 19 & 16 & 13 & 40 & 0 & 18 & 212 \\
\hline 1988 & 34 & 21 & 28 & 5 & 18 & 5 & 18 & 2 & 21 & 8 & 13 & 39 & 0 & 26 & 238 \\
\hline 1989 & 26 & 14 & 30 & 9 & 8 & 3 & 25 & 3 & 17 & 18 & 12 & 29 & 0 & 11 & 205 \\
\hline 1990 & 19 & 7 & 23 & 8 & 16 & 3 & 21 & 6 & 18 & 19 & 6 & 15 & 0 & 13 & 174 \\
\hline 1991 & 19 & 11 & 23 & 7 & 12 & 6 & 14 & 5 & 8 & 11 & 10 & 28 & 0 & 16 & 170 \\
\hline 1992 & 6 & 6 & 6 & 5 & 6 & 6 & 7 & 5 & 0 & 0 & 0 & 0 & 0 & 6 & 53 \\
\hline 1993 & 9 & 6 & 9 & 6 & 10 & 8 & 7 & 0 & 9 & 6 & 6 & 18 & 0 & 14 & 108 \\
\hline 1994 & 16 & 13 & 13 & 8 & 10 & 6 & 7 & 5 & 0 & 0 & 0 & 0 & 0 & 6 & 84 \\
\hline 1995 & 0 & 0 & 3 & 0 & 10 & 7 & 10 & 5 & 8 & 6 & 6 & 17 & 0 & 12 & 84 \\
\hline 1996 & 5 & 5 & 8 & 5 & 12 & 5 & 10 & 5 & 7 & 9 & 5 & 13 & 0 & 9 & 98 \\
\hline 1997 & 5 & 6 & 5 & 5 & 6 & 5 & 8 & 5 & 5 & 5 & 4 & 8 & 0 & 8 & 75 \\
\hline 1998 & 9 & 5 & 10 & 7 & 11 & 6 & 10 & 5 & 5 & 8 & 6 & 12 & 0 & 9 & 103 \\
\hline 1999 & 8 & 6 & 14 & 8 & 13 & 6 & 9 & 3 & 5 & 6 & 6 & 13 & 0 & 5 & 102 \\
\hline 2000 & 13 & 6 & 14 & 7 & 14 & 5 & 9 & 5 & 6 & 5 & 8 & 16 & 0 & 11 & 119 \\
\hline 2001 & 0 & 0 & 15 & 7 & 15 & 5 & 11 & 6 & 5 & 6 & 9 & 18 & 0 & 15 & 112 \\
\hline 2002 & 0 & 0 & 7 & 2 & 5 & 6 & 8 & 4 & 6 & 6 & 5 & 10 & 0 & 10 & 69 \\
\hline 2003 & 0 & 0 & 7 & 6 & 7 & 7 & 6 & 5 & 6 & 5 & 5 & 7 & 0 & 16 & 77 \\
\hline 2004 & 9 & 7 & 11 & 9 & 9 & 6 & 9 & 5 & 7 & 7 & 8 & 12 & 0 & 15 & 114 \\
\hline 2005 & 0 & 0 & 9 & 7 & 8 & 6 & 6 & 5 & 6 & 7 & 8 & 11 & 0 & 15 & 88 \\
\hline 2006 & 6 & 5 & 7 & 5 & 7 & 7 & 8 & 5 & 2 & 1 & 5 & 11 & 0 & 11 & 80 \\
\hline
\end{tabular}

\section{Community dynamics}

Dynamics were analysed with respect to, first, community interactions and, second, environmental relationships. Community interactions, i.e. relationships between principal components aggregated by year or area, were analysed by means of phase diagrams of principal components. The rationale was that ordered relationships indicate interactions and hence interdependence. Three types of ordered patterns can be expected: first, configurations reflecting linear gradients or clines, second, cyclic relationships, and third, disrupt configurations. Disrupt configurations indicate shifts between two states, whereas cyclic relationships indicate community state transitions dependent on biological constraints of resilience and persistence. Gradients were analysed by means of correlations and the degree of order in phase diagrams was assessed by subsuming distance values between consecutive years. Distance values on standardised variables were compared to a distribution of distance values obtained from a randomised input data set with 150 permutations (see section before). The assumption is that a random configuration should be bare of order and thus have higher subsumed distance values.

Environmental relationships were analysed by correlations of the annually and regionally aggregated principal components. As a first step, environmental relationships were analysed by means of best correlations for the available time series. Second, with higher 
TABLE 2. German autumn survey abundance indices (in thousands) for selected demersal species from West and East Greenland (taken partly from ICES, MS 2006).

\begin{tabular}{|c|c|c|c|c|c|c|c|c|c|c|c|c|c|c|}
\hline \multirow[b]{2}{*}{ Year } & \multicolumn{2}{|c|}{$\begin{array}{c}\text { Atlantic cod } \\
\text { Gadus morhua }\end{array}$} & \multicolumn{2}{|c|}{$\begin{array}{l}\text { Atlanitc wolffish } \\
\text { Anarhichas lupus }\end{array}$} & \multicolumn{2}{|c|}{$\begin{array}{c}\text { Spotted wolffish } \\
\text { A. minor }\end{array}$} & \multicolumn{2}{|c|}{$\begin{array}{l}\text { Starry ray } \\
\text { A. radiata }\end{array}$} & \multicolumn{2}{|c|}{$\begin{array}{l}\text { American plaice } \\
\text { H. platessoides }\end{array}$} & \multicolumn{2}{|c|}{$\begin{array}{c}\text { Golden redfish } \\
\text { Sebastes marinus }\end{array}$} & \multicolumn{2}{|c|}{$\begin{array}{l}\text { Deep sea redfish } \\
\text { S. mentella }\end{array}$} \\
\hline & West & East & West & East & West & East & West & East & West & East & West & East & West & East \\
\hline 1982 & 92274 & 8093 & 23062 & 1921 & 1511 & 277 & 9695 & 170 & 78026 & 4946 & 132361 & 546825 & 3114 & 87467 \\
\hline 1983 & 50202 & 7990 & 15426 & 3395 & 868 & 317 & 6997 & 0 & 115443 & 11366 & 28713 & 420395 & 8885 & 86596 \\
\hline 1984 & 16681 & 6598 & 11024 & 6791 & 787 & 513 & 6319 & 493 & 89606 & 7930 & 24096 & 64756 & 5405 & 111190 \\
\hline 1985 & 59347 & 12409 & 12738 & 12866 & 629 & 514 & 7878 & 181 & 62398 & 18125 & 45475 & 279750 & 809 & 172092 \\
\hline 1986 & 145681 & 15227 & 12090 & 11297 & 1034 & 544 & 6704 & 218 & 111511 & 17477 & 43317 & 446023 & 3335 & 150787 \\
\hline 1987 & 786390 & 41633 & 9575 & 20068 & 949 & 622 & 3336 & 244 & 56247 & 17802 & 13156 & 595933 & 14764 & 88041 \\
\hline 1988 & 626494 & 23583 & 10553 & 14056 & 936 & 568 & 7149 & 161 & 33563 & 13673 & 14291 & 174987 & 8818 & 252234 \\
\hline 1989 & 358726 & 91734 & 10564 & 9113 & 841 & 470 & 19412 & 229 & 39171 & 9924 & 9161 & 225548 & 305 & 298244 \\
\hline 1990 & 34525 & 25252 & 10440 & 11256 & 623 & 698 & 13328 & 553 & 29103 & 15457 & 4998 & 778175 & 4650 & 44700 \\
\hline 1991 & 4802 & 10406 & 9861 & 10139 & 717 & 474 & 4828 & 257 & 23785 & 22342 & 3724 & 107685 & 2425 & 970004 \\
\hline 1992 & 2042 & 656 & 13168 & 5438 & 311 & 202 & 10713 & 202 & 24105 & 6695 & 2197 & 32623 & 157 & 60065 \\
\hline 1993 & 1436 & 3297 & 8848 & 16553 & 527 & & 4127 & 382 & 13280 & 29753 & 1189 & 64891 & 189 & 1384034 \\
\hline 1994 & 572 & 803 & 11972 & 5521 & 359 & 1257 & 4777 & 1060 & 11495 & 2492 & 1266 & 3350 & 680 & 77894 \\
\hline 1995 & 276 & 7191 & 3146 & 17573 & 35 & 1003 & 614 & 355 & 3885 & 32913 & 302 & 42968 & 1826 & 2503280 \\
\hline 1996 & 809 & 1447 & 7360 & 32244 & 184 & 1304 & 2214 & 607 & 12189 & 46309 & 1770 & 27757 & 11464 & 4499169 \\
\hline 1997 & 315 & 4153 & 15062 & 28289 & 413 & 1040 & 6726 & 1083 & 24842 & 33307 & 2072 & 24501 & 36518 & 6907882 \\
\hline 1998 & 1723 & 1671 & 10142 & 21644 & 314 & 1063 & 3237 & 437 & 23869 & 27757 & 949 & 175011 & 4068 & 2893235 \\
\hline 1999 & 912 & 2769 & 16614 & 24721 & 300 & 759 & 3982 & 1166 & 19582 & 23676 & 1163 & 34192 & 2426 & 583992 \\
\hline 2000 & 1926 & 4816 & 10840 & 14842 & 630 & 653 & 2913 & 872 & 14066 & 26553 & 2582 & 62429 & 23509 & 721761 \\
\hline 2001 & 8211 & 8244 & 9542 & 31091 & 222 & 754 & 1431 & 1495 & 20493 & 25173 & 2502 & 105213 & 20134 & 864108 \\
\hline 2002 & 4121 & 9691 & 7307 & 25125 & 196 & 496 & 1073 & 712 & 11879 & 23686 & 984 & 348746 & 1374 & 999154 \\
\hline 2003 & 5632 & 19904 & 12921 & 27953 & 156 & 561 & 1276 & 779 & 35332 & 20418 & 3326 & 150922 & 11605 & 3323769 \\
\hline 2004 & 31607 & 17540 & 20055 & 33823 & 622 & 547 & 3032 & 587 & 59069 & 22573 & 3672 & 197181 & 9109 & 2898160 \\
\hline 2005 & 62774 & 79455 & 14571 & 18798 & 538 & 759 & 1743 & 527 & 28723 & 15489 & 7866 & 298952 & 3101 & 2687601 \\
\hline 2006 & 220473 & 61717 & 10478 & 9385 & 944 & 1623 & 2331 & 637 & 28556 & 8803 & 10974 & 327484 & 16616 & 1322880 \\
\hline
\end{tabular}

temporal resolution, a moving section of the time series was analysed using moving window correlations (MWC) (Fock and Greve, 2002). By means of compartmenting the data set, this technique accomplishes detection of short-term impacts embedded in time-series only during certain periods. Moving windows correlations were applied to time-series detrended by means of first order differences, and spatially disaggregated into West and East Greenland to account for regional variation. Correlations for the entire available time series were carried out with and without detrending. The sign of the MWC patterns to be considered was determined by the sign of the correlation in the entire time series.

\section{Results}

\section{Principal components of community structure}

The first eight components satisfy the Kaiser criterion with eigenvalues $>1$, whereas four components are retained applying Cattel's rule (Table 3, for explanations see "Community analysis"). According to Stahel's rationale, four principal components are required to describe dynamics of the five most abundant taxa. The five most abundant taxa represent about $93 \%$ of all individuals sampled. The corresponding first four principal components account for $60 \%$ of total variability of the data set. Though at times very abundant in the catches, capelin was not correlated with any of the first principal components.

Components prin 1 and prin2 have a strong relationship to the most abundant taxa, i.e. deep-sea redfish and juvenile redfish, respectively, whereas prin3 and prin4 have relationships to several taxa and thus represent aspects of joint variability. The group for prin 3 comprises juvenile redfish, cod, golden redfish, American plaice and Atlantic wolffish. Prin4 is strongly related to deepsea redfish, cod, and American plaice. The non-redfish 
TABLE 3. Principal components analysis results including species correlations with eigenvectors. For species, percentage by number in the survey catches 1981-2006 is indicated. Eigenvalues for other principal components are prin $5=2.45$, prin $6=1.88$, prin7 $=1.46$, prin8 $=1.16, \operatorname{prin} 9=0.96, \operatorname{prin} 10=0.77$, $\operatorname{prin} 11=0.65, \operatorname{prin} 12=0.56, \operatorname{prin} 13=0.54, \operatorname{prin} 14=0.42$, $\operatorname{prin} 15=0.40$, and $\operatorname{prin} 16=0.37$.

\begin{tabular}{lrrrrc}
\hline & Prin1 & Prin2 & Prin3 & Prin4 & Catch \% \\
\hline Eigenvalue & 8.98 & 6.67 & 5.12 & 3.02 & \\
\% expl. variance & 22.5 & 16.7 & 12.9 & 7.5 & \\
$\begin{array}{l}\text { Deep-sea redfish } \\
\text { Sebates mentella }\end{array}$ & $0.79^{*}$ & -0.1 & -0.2 & $0.46^{*}$ & 34.1 \\
Redfish, juv. $<17 \mathrm{~cm}$ & 0.23 & $0.66^{*}$ & $0.4^{*}$ & -0.23 & 30.1 \\
$\begin{array}{l}\text { Sebastes spp. } \\
\text { Golden redfish }\end{array}$ & $0.39^{*}$ & $-0.42^{*}$ & $0.48^{*}$ & $-0.55^{*}$ & 13.2 \\
$\begin{array}{l}\text { S. marinus } \\
\text { Atlantic cod }\end{array}$ & -0.28 & $-0.41^{*}$ & $0.5^{*}$ & $0.38^{*}$ & 8.9 \\
$\begin{array}{l}\text { Gadus morhua } \\
\text { American plaice }\end{array}$ & -0.01 & 0.14 & $0.41^{*}$ & $0.43^{*}$ & 4.0 \\
$\begin{array}{l}\text { H. platessoides } \\
\text { Atlantic wolffish }\end{array}$ & 0.12 & 0.05 & 0.29 & 0.12 & 1.4 \\
$\begin{array}{l}\text { Anarhichas lupus } \\
\text { Starry ray }\end{array}$ & & & & & \\
$\begin{array}{l}\text { Amblyraja radiata } \\
\text { Spotted wolffish }\end{array}$ & -0.10 & 0.15 & 0.15 & 0.25 & 0.4 \\
Anarhichas minor & 0.01 & -0.01 & 0.07 & 0.07 & 0.1 \\
\hline $\begin{array}{l}\text { Correlations for }<0.30 \\
\text { Ant }\end{array}$ & & & & & \\
\hline
\end{tabular}

* Correlations for $r<|0.30|$ is not significant at the $p=0.05$ level.

species related to prin 3 and prin 4 have strong negative (cod) or are weakly correlated to prin1 and prin2. In turn, golden redfish is negatively correlated with prin4, opposite to cod. This indicates that prin 1/prin2 vs. prin3/prin4 and prin 1 vs. prin4 represent very different aspects of assemblage dynamics.

Correlations by principal component indicate that Nuuk ATA is significantly related with $\operatorname{prin} 1(r=0.66)$ and prin4 $(r=0.61)$, in particular for East Greenland, as indicated also by significant detrended correlations (Table 4). For prin1, the relationship is very pronounced from 1983 to 1992 , whereas for prin4 a strong relationship exists from 1993 and onwards (Fig. 2). Despite their similar temporal trends, both principal components are spatially separated (Fig. 3). The overall picture shows that prin1 is centred in East Greenland, but also occurs marginally along the West Greenland slope. In turn, prin4 is concentrated on the West Greenland shelf with a tendency towards inshore areas and also occurs on bank habitats along the East Greenland coast.
Prin2 is significantly positively correlated both with the phytoplankton colour index composite (PCI composite) available for East Greenland and with fishing mortality of cod (Table 4, Fig. 4). The positive relationship to fishing mortality of cod in West Greenland indicates a cod-redfish relationship. The East Greenland component of prin2 (prin2east) correlates fairly well with the PCI composite, which originated from CPR region B7 off east Greenland. The spatial distribution of prin2 is characterised by a conspicuous focus of prin2 in southern East Greenland, i.e. strata 5 and southern part of 6 (Fig. 3). In West Greenland, high density for prin2 is recorded in stratum 1.

Prin3 is negatively related to fishing mortality $F$, though not in the detrended series probably due to short time series coverage (Table 4). Until 1992, there is fair congruence between $F$ and the inverted curve for prin3 (Fig. 5A). However, no regionally significant correlations are obtained (Table 4), although both prin3 and cod catches are concentrated at West Greenland. A further 
TABLE 4. Impact factor correlations using catches, mortality and effort data until 1992. Statistics provided for correlations by principal component. In each cell, the first line is for correlations of original (and detrended) series, and the second line is for regionally split correlations of original (and detrended) series.

\begin{tabular}{lcccc}
\hline \hline Impact & Prin1 & Prin2 & Prin3 & Prin4 \\
\hline Nuuk air temperature & $0.66^{* * *}\left(0.42^{*}\right)$ & -0.03 & -0.11 & $0.61^{* *}(-)$ \\
anomalies (Nuuk ATA) & 1 east $0.52^{* *}\left(0.53^{* *}\right)$ & & & 4east $0.51^{*}\left(0.44^{*}\right)$ \\
Offshore cod catches & -0.35 & -0.11 & -0.07 & -0.009 \\
Fishing mortality & $-0.63^{*}(-)$ & $0.77^{* *}\left(0.62^{*}\right)$ & $-0.67^{* /(-)}$ & -0.21 \\
& $-(-)$ & 2 west $0.71(-)$ & $-/(-)$ & \\
Inshore fishing effort & -0.29 & -0.25 & 0.26 & 0.48 \\
Phytoplankton colour & -0.15 & 0.48 & $-0.53^{*}(-)$ & -0.11 \\
index (PCI) Jul-Aug & & & 3 west $-0.51^{*}(-)$ & \\
& & & 3 east $-(0.64 *)$ & \\
PCI composite & 0.06 & $0.56^{*}(-)$ & $-0.84^{* * *}\left(-0.63^{*}\right)$ & -0.07 \\
& & 2 east $0.63^{*}(-)$ & 3 west $-0.82^{* *}(-)$ & \\
\hline
\end{tabular}

$*, * *, * * *$ denote the significance levels at $p=0.05,0.01$ and 0.001 , respectively.

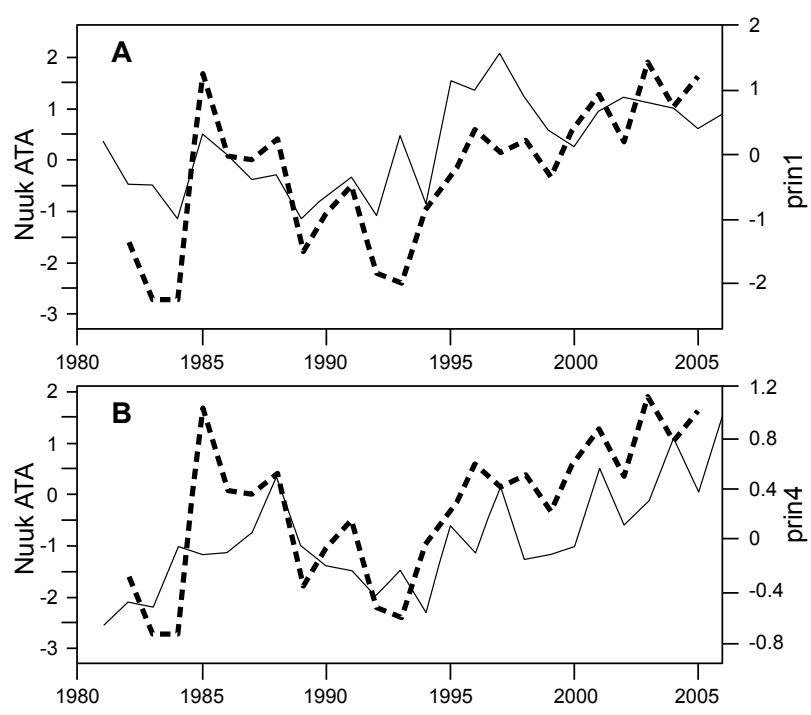

Fig. 2. Temporal trends for Nuuk annual air temperature anomalies (Nuuk ATA, broken line) and (A) Prin1 (solid line) and (B) Prin4 (solid line).

focus appears in bank habitats in stratum 5 and in stratum 6 (Fig. 3).

Further strong negative correlations appear for PCI. These correlations with regard to West Greenland regional prin3 (prin3west) are likely to be spurious, since PCI was valid only for East Greenland. Accordingly, the graphical display shows little congruence (Fig. 5B). A significant positive correlation is indicated for East Greenland in the detrended time series (Table 4).
Cod catches are negatively correlated to all principal components, indicating a negative though not significant impact of the target fisheries on all species represented by the first four principal components. Partial correlations for cod catches decline in all cases, when Nuuk ATA is taken as partial variable, so that climate does not override a potentially stronger impact of cod catches. Hereafter, fishing mortality is taken to represent effects of fisheries (Fig. 6).

Based on eigenvector loadings and environmental correlations prin1 is characterised as the climate component of redfish dynamics, however stronger for deep-sea redfish than for golden redfish, centred in East Greenland (Fig. 3). Correspondingly, prin4 represents the climate component of the species group of cod, American plaice and deep-sea redfish, centred in West Greenland. Prin2 represents the component of juvenile redfish in relation to primary production and fisheries, and prin3 is the component assigned to fisheries impacts and primary production for cod, golden redfish, and American plaice. For cod, more variability is expressed by means of variance components from prin 3 than from prin4. For deep-sea redfish, prin1 explains much more variance than prin4.

\section{Community dynamics}

Phase diagrams indicate non-random interaction patterns for prin1-prin2, prin1-prin4, prin2-prin4, and prin2-prin3, either in terms of significant correlations or in terms of significantly low subsumed distance values 

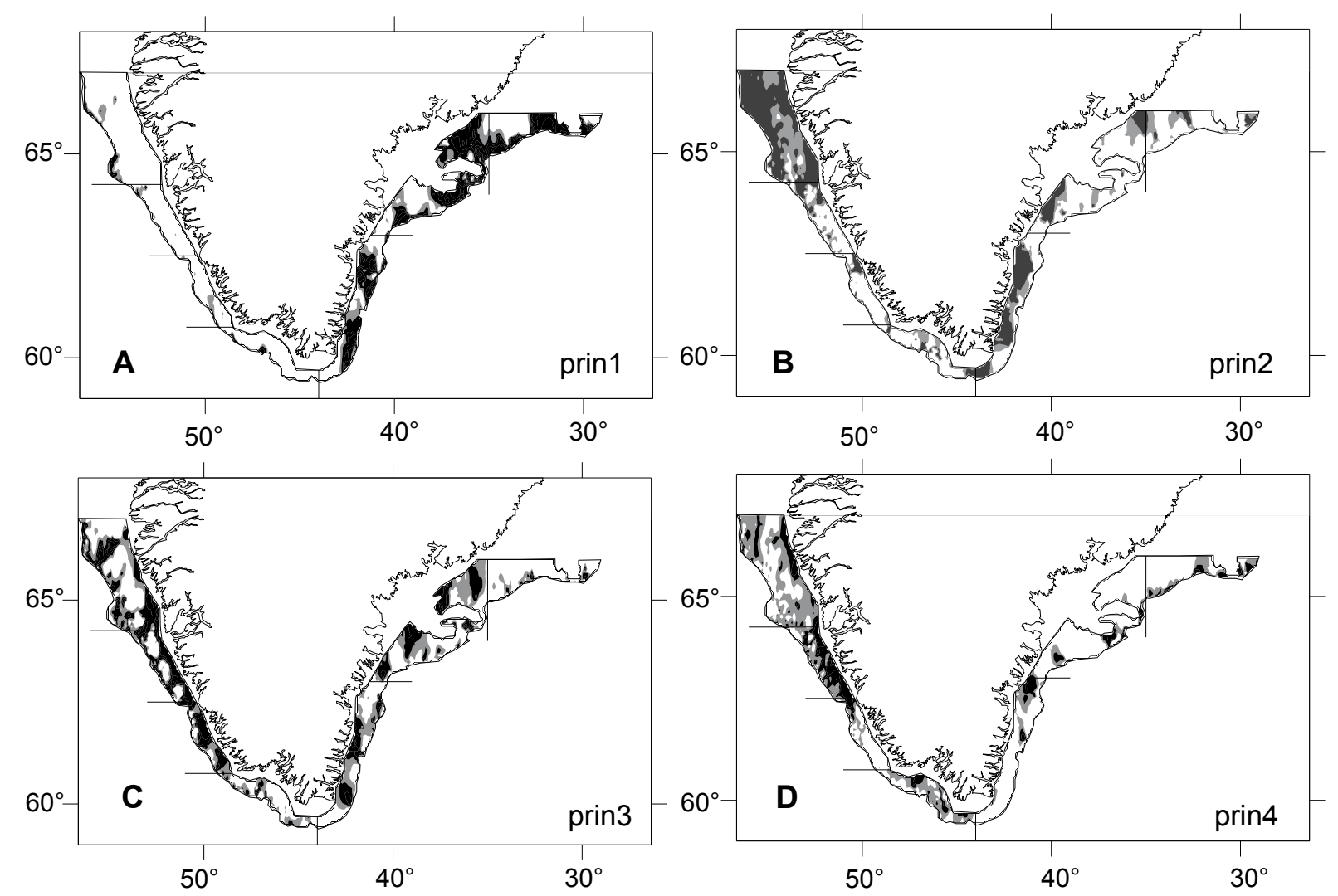

Fig. 3. Spatial distribution covering the period 1981-2006 for principal components (A) prin1, (B) prin2, (C) print3, and (D) prin4. Shading indicates positive values in two levels, i.e. $0-1$ (grey) and $>1$ (black). Positive values indicate higher than average performance for each respective principal component and for its associated species (Backhaus et al., 1990).
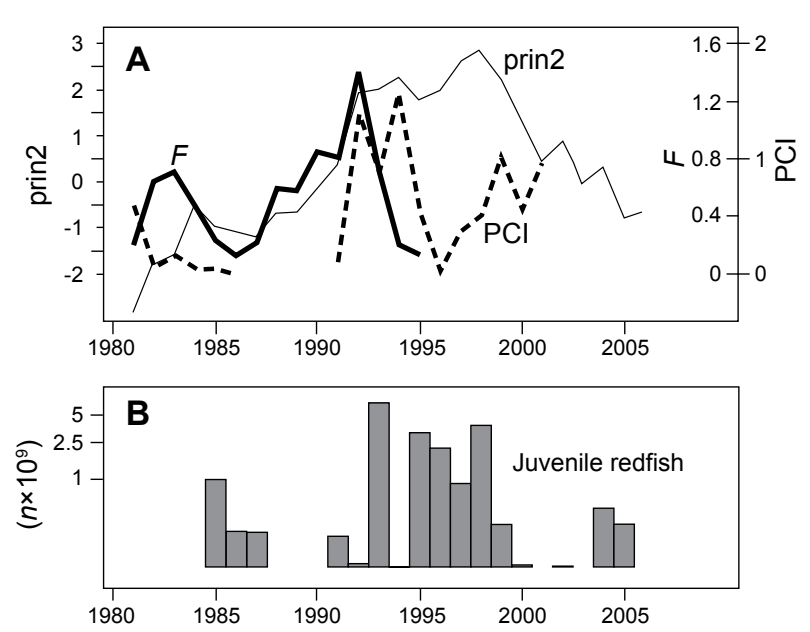

Fig. 4. Time series (A) for principal component prin2 (thin solid line), fishing mortality $F$ (thick solid line), phytoplankton colour index (PCI, broken line), and (B) for survey abundance index $\left(\mathrm{n} \times 10^{9}\right)$ for juvenile redfish (histogram).
(Table 5). Only for prin3-prin4, no significant relationship was obtained.

The relationship between prin 1 and prin 2 indicates a positive closed cycle between juvenile and adult redfish with a very low value for subsumed distances (Fig. 7A). Overlaying sea temperature values indicates that positive loads on prin 1 are obtained at warmer temperatures.

For prin1-prin4 the significant positive correlation (Table 5) is mainly due to a strong gradient for the East Greenland components, which have higher loads at increased temperature (Fig. 7C1). The components for West Greenland are less correlated and resemble a negative incomplete cycle without a clear relationship to Nuuk ATA.

Patterns including prin2 are not cyclic, but for the West Greenland components show strong negative gradients with very low subsumed distance values for prin2- 

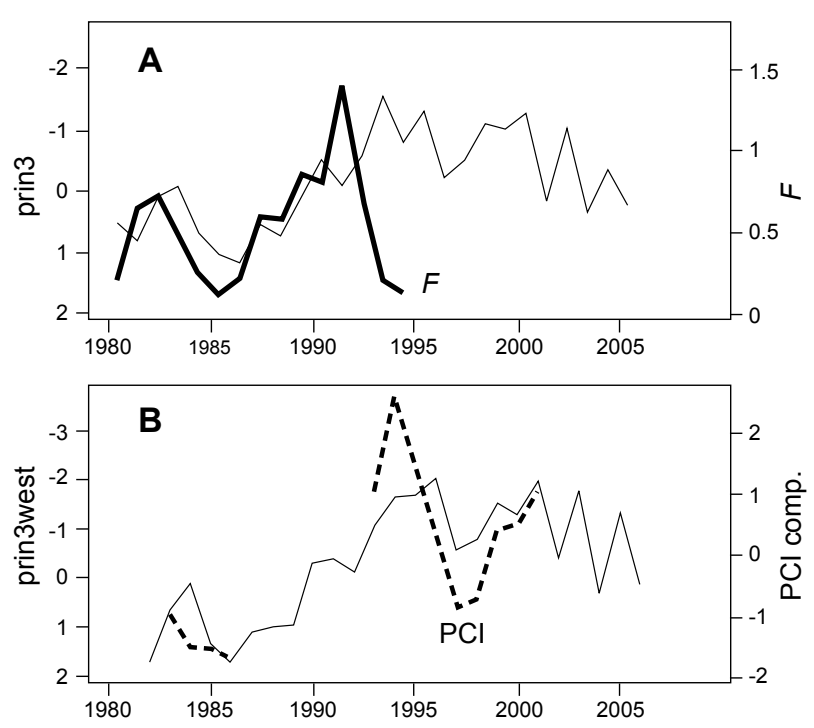

Fig. 5. Time series for (A) principal component prin3 (thin solid line) and fishing mortality $F$ (thick solid line) until 1995, and (B) the regional component prin3west with the PCI composite, a likely spurious correlation since PCI is a time series for East Greenland. Prin3 and prin 3 west inversed.

prin3 (21.6) and for prin2-prin4 (19.7) without a clear relationship to Nuuk ATA (Fig. 7B1 and 7B3). In turn, the correlation prin2-prin4 for East Greenland is positive, and higher loads are further correlated to Nuuk ATA.

The MWC-analysis of environmental relationships for West Greenland show two short periods of positive significant climate effects for prin1 and prin 4 which are not coinciding (Table 6). Firstly, a significant effect is observed for prin4 (1981-1985), thereafter only for prin1 (1988-1996). No other significant correlations with positive sign appear. Only marginal effects are observed for mortality $F$ and prin3, though correlations obtained for the entire time series were significant (Table 4).

The analysis of environmental driving forces for East Greenland shows significant correlations with climate both for prin1 and prin4, for prin1 covering almost the entire time series (Table 7). Significant periods for prin1 occur from 1982-1991, 1993-1999 and further after 2000 to 2005, for prin4 from 1999-2005, respectively. A negative relationship for prin 3 to mortality $F$ appears from 1984-1990, paralleled by a positive relationship between prin2 and $F$ from 1985 to 1991. For prin2 and prin3, significant correlations with PCI are indicated in particular for the mid-1990s until 2001.

\section{Reconciling community dynamics}

Phase diagrams and MWC-analysis show complementary patterns. For West Greenland, strong negative

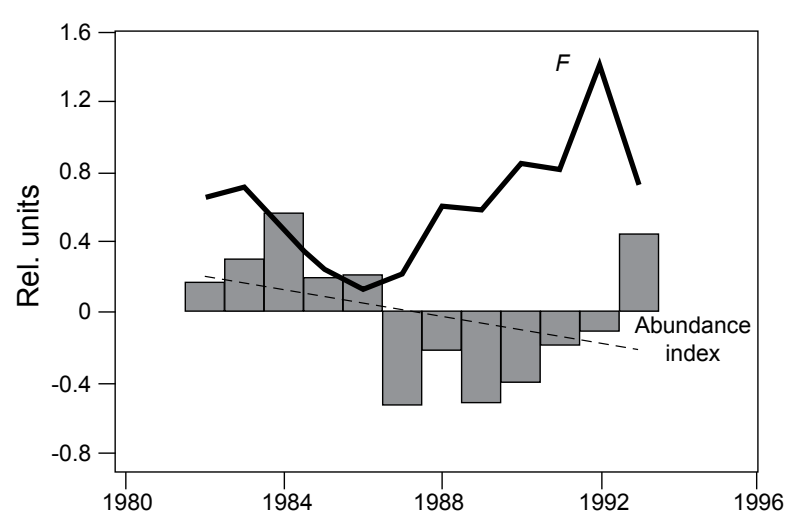

Fig. 6. Fishing mortality $F$ (solid lines) and cod abundance index (histogram) according to Myers et al. (1997). The abundance index is defined as the log ratio of numbers at age 3 from VPA and survey, i.e. log $\left(\mathrm{VPA}_{\text {age } 3} /\right.$ Survey $\left._{\text {age3 }}\right)$. Abundance index becomes negative as $F$ increases rapidly, i.e. VPA underestimates mortality. The linear trend for the abundance index (dashed line) is negative for the time period covering the collapse of cod stocks off Greenland. Mortality data as in Fig. 5A.

relationships for prin2-prin3, prin1-prin4 and prin2prin4 indicate strong relationships between redfish, cod and American plaice, all significant in terms of ordered subsumed distances (Table 5, Fig. 7B1, 7B2 and 7B3). No significant patterns to Nuuk ATA appear in the phase diagrams and climate is significantly linked to dynamics in terms of MWC only for a short period. This puts an emphasis on biological interactions, e.g. competitive effects between all four principal components, and on cycles as for the interaction between juvenile redfish and adult redfish, i.e. prin2-prin1.

In turn, positive gradients between redfish, cod and American plaice for East Greenland indicate dependence on abiotic factors but little competitive effects, paralleled by the extended periods of significant correlations in the MWC analysis. Phase diagrams show a relationship to Nuuk ATA, so that relationships could be temperature driven. Only two relationships appear to be significant in terms of ordered subsumed distances. Fishing mortality appears naturally as a negative factor for prin 3 and as a positive factor for prin2, indicating that juvenile redfish are negatively related to cod as predator (Fig. 7B1). Fishing mortality is negatively related to the abundance index of Myers et al. (1997), which becomes negative as $F$ increases sharply in 1987 (Fig. 6) coinciding with the significant correlation indicated for prin 3 in the MWC analysis. This congruence indicates that $F$ is decisive to characterise the collapse of the cod stock, but is likely underestimated, which could explain that correlations for $F$ in detrended time series were not significant for prin3. 
TABLE 5. Phase diagram statistics based on annual means. Coordinates from randomised inputs for prin1 and prin2 have, respectively, a mean standardised ordered subsumed distance of 30.7, corresponding $5 \%$ and $1 \%$ percentiles are 25.9 and 24.6 . Selected patterns depicted in Fig. 7.

\begin{tabular}{ccc}
\hline \hline $\begin{array}{l}\text { Overall relationship and } \\
\text { regional splitting }\end{array}$ & $\begin{array}{c}\text { Standardised ordered } \\
\text { subsumed distance }\end{array}$ & $\begin{array}{c}\text { Correlation coefficient } \\
r\end{array}$ \\
\hline prin1-prin2 & $22.0^{* *}$ & 0.38 \\
prin1-prin3 & 29.8 & -0.31 \\
prin1-prin4 & 28.6 & $0.5^{*}$ \\
p1p4east & $23.9^{* *}$ & $0.85^{* * *}$ \\
p1p4west & $25.7^{*}$ & -0.19 \\
prin2-prin3 & $23.0^{* *}$ & $0.69^{* *}$ \\
p2p3east & 30.1 & -0.01 \\
p2p3west & $21.6^{* *}$ & $-0.65^{* *}$ \\
prin2-prin4 & $22.3^{* *}$ & 0.04 \\
p2p4east & $20.4^{* *}$ & $0.58^{*}$ \\
p2p4west & $19.7^{* *}$ & $-0.66^{* *}$ \\
prin3-prin4 & 29.3 & 0.01 \\
\hline
\end{tabular}

$*, * *, * * *$ denote the significance levels at $p=0.05,0.01$ and 0.001 , respectively.

\section{Discussion}

In this study, four principal components were employed to analyse community dynamics, explaining $60 \%$ of total variance. In turn, the corresponding taxa accounted for $93 \%$ of abundance variability. Thus, the subspace of principal components can be distinguished as an 'ideal' community from the original time series. Within this subspace, the first two principal components represent congeners, reflecting the numerical dominance of redfish species in the ecosystem. Principal components prin 3 and prin 4 share contributions from several species and thus are community components, indicating similarities between species. However, the explained variance by prin 3 and prin 4 is small compared to prin 1 and prin 2 . Among the environmental factors available for analysis, climate which was assigned to principal components prin 1 and prin 4 , accounted for $30 \%$ of community variance. Productivity and fisheries impact were each related to both prin 2 and prin 3 , accounting for $29.6 \%$ of variability, respectively.

\section{Effects of bottom-up forcing and fisheries}

In the moving window analysis, climate was the predominant factor. Additional significant effects only occurred associated with climate, i.e. the effect of fisheries and of productivity in East Greenland. For West Green- land, the effect of fisheries was not significant in terms of MWCs. For the North Sea and the Newfoundland shelf associated effects of climate and overfishing have been described for single populations to account for unexplained gains and losses (Beaugrand et al., 2003; Rose 2004). Similarly, quantifying driving forces on community level for the Gulf of Alaska ecosystem showed the predominance of climate forcing for boreal ecosystems as compared to fisheries (Anderson and Piatt, 1999).

For the Greenland offshore ecosystem, Stein and co-workers (Stein and Lloret, 1995; Stein and Borovkov, 2004) identified three distinct periods in the longterm performance of cod recruitment, i.e. (1) $1950 \mathrm{~s}$ and 1960 s, (2) 1970s and 1980s, and (3) 1990s to now. Phase (1) was relatively warm, whereas during phase (2) cooling occurred. Phase (3) was negatively defined by cod recruitment failure. The switch between phase (2) and phase (3) is also met in the MWC analysis on community level, thus indicating linkage of processes on population and on community level. The switch between phase (1) and phase (2) is also recognized in ichthyoplankton data from Pedersen and Rice (2002), indicating that recruitment is climate dependent at low stock densities (Brander, 2005).

In the Gulf of Alaska ecosystem, opposite changes have been observed as compared to Greenland, i.e. an 

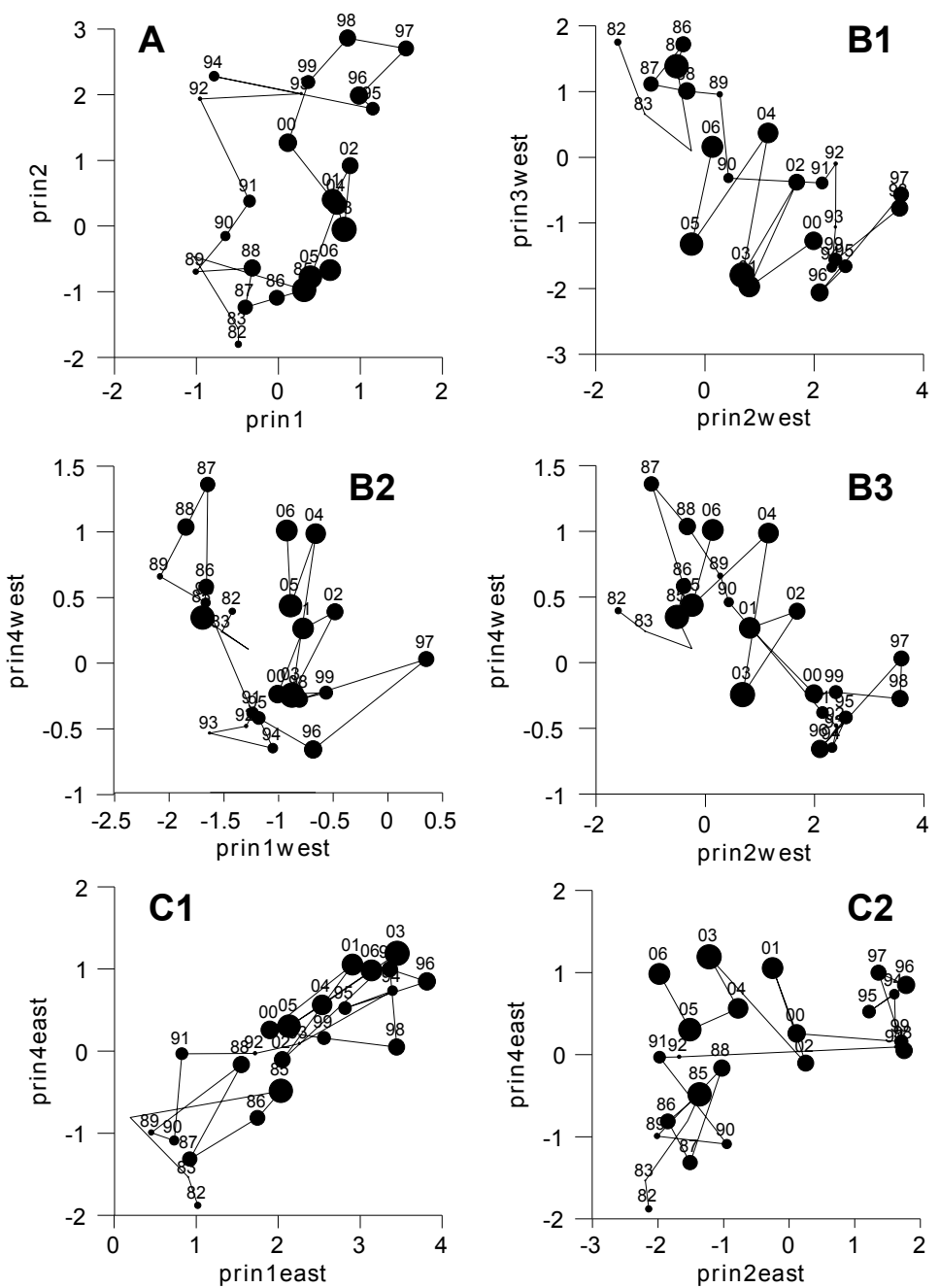

Fig. 7. Phase diagrams (A) without, and (B,C) with regional splitting. (A) prin1 and prin2, (B1) prin2west and prin3west, (B2) prin1west and prin4west, (B3) prin2west and prin4west, (C1) prin1east and prin4east and $(\mathbf{C 2})$ prin2east and prin4east. Bubble size is directly proportional to the NUUK ATA. Years indicated by two digits. '...west' and '...east' indicate regional splitting.

increase in groundfish stocks and a decrease in shrimp stocks since the 1990s related to climate fluctuations as indicated by the regional North Pacific Pressure Index (Anderson and Piatt, 1999; Anderson, 2000), referring to phase (3). This coincidence with Greenland's ecosystems underlines the role of climate as major driving force for arctic ecosystems and a likely seesaw mechanism as observed in climatological time series on the Northern Hemisphere (Meehl and van Loon, 1979). North Pacific and North Atlantic oscillation patterns are known to be negatively correlated, at least since the 1960s (Schwing et al., 2003; Ogi et al., 2004). The climate proxy of this study, i.e. Nuuk ATA, is linked to the corresponding North Atlantic Oscillation Index (NAOI) (Buch et al.,
2003; Stein, 2004). This and further synchronous changes observed in the Barents Sea and the North Pacific (Lehoudey et al., 2006) indicate, that arctic and sub-arctic ecosystems are linked by a interdependent system of atmospheric forcing, i.e. teleconnections.

Besides climate, fisheries and productivity were identified as further driving forces. In particular, prin2, i.e. juvenile redfish, and prin3, i.e. mainly cod and American plaice, was related to plankton productivity during summer. For juvenile redfish, an effect during the plankton stage is likely, i.e. for larval and unsettled 0-group specimens. For deep-sea redfish, larvae are extruded along Reykjanes Ridge during April to 
TABLE 6. Moving-window correlations by pentade and interpretation of resulting patterns as driving forces for West Greenland (GL). Values including summer survey 1981 in parentheses. p1w-prin1west, chl78 - PCI for July and August, nuuk - Nuuk ATA, F - fishing mortality.

\begin{tabular}{lccccccc}
\hline \hline Pentade & Driving force & $\mathrm{p} 1 \mathrm{w}-\mathrm{nuuk}$ & $\mathrm{p} 2 \mathrm{w}-\mathrm{chl} 78$ & $\mathrm{p} 2 \mathrm{w}-F$ & $\mathrm{p} 3 \mathrm{w}-\mathrm{ch} 178$ & $\mathrm{p} 3 \mathrm{w}-F$ & $\mathrm{p} 4 \mathrm{w}-\mathrm{nuuk}$ \\
\hline $1981-1985$ & $(0.3)$ & $(-0.7)$ & $(0.6)$ & $(-0.6)$ & $(0.2)$ & $\left(0.96^{*}\right)$ \\
$1982-1986$ & -0.7 & -0.3 & 0.2 & -0.2 & -0.6 & 0.4 \\
$1983-1987$ & -0.8 & & -0.7 & & -0.5 & -0.1 \\
$1984-1988$ & -0.9 & & 0.6 & & -0.7 & -0.1 \\
$1985-1989$ & 0.1 & & 0.3 & & -0.4 & 0.3 \\
$1986-1990$ & 0.6 & & 0.3 & & -0.2 & 0.2 \\
$1987-1991$ & 0.7 & & -0.6 & & -0.4 & -0.1 \\
$1988-1992$ & & $0.99 *$ & & -0.7 & & 0.1 & -0.4 \\
$1989-1993$ & 0.6 & & & & & -0.5 \\
$1990-1994$ & Climate & 0.7 & & & & & -0.3 \\
$1991-1995$ & 0.6 & -0.1 & & 0.3 & & 0.3 \\
$1992-1996$ & $0.89 *$ & -0.3 & & -0.5 & & -0.2 \\
$1993-1997$ & -0.5 & 0.3 & & 0.2 & & -0.9 \\
$1994-1998$ & -0.2 & 0.5 & & 0.6 & & -0.6 \\
$1995-1999$ & -0.2 & 0.2 & & 0.2 & & -0.6 \\
$1996-2000$ & -0.6 & 0.1 & & -0.1 & & -0.4 \\
$1997-2001$ & -0.2 & -0.7 & & -0.9 & & 0.3 \\
$1998-2002$ & -0.7 & & & & & 0.3 \\
$1999-2003$ & -0.8 & & & & & -0.5 \\
$2000-2004$ & -0.8 & & & & & -0.7 \\
$2001-2005$ & -0.9 & & & & -0.9 \\
$2002-2006$ & -0.9 & & & & -0.9 \\
\hline
\end{tabular}

* One-sided critical value for $r$ is 0.73 at $p=0.05, \mathrm{df}=4$; non-significant values truncated to one decimal digit.

May (Saborido-Rey et al., 2004; Pedchenko, 2005). Anticlockwise circulation with the Irminger current is the major pathway for their distribution. This mechanism is likely to accelerate during high NAO periods, when westerly winds intensify the rotation of the Irminger gyre so that increased Ekman transport provides onshore transport (Buch et al., 2003). During periods of high NAOI in the mid-1990s and at the beginning of the 2000s, significant MWCs with regard to PCI at East Greenland were obtained (Table 7). In line with this argument is the vertical temperature distribution in the centre of the Irminger gyre (Pedchenko, 2005). During the mid-1990s cold water was encountered in the centre of the Irminger Sea, indicating central upwelling as a consequence of the Ekman onshore transport. Measurements of geostrophic pressure further corroborate the mechanism of intensive onshore transport for the Irminger sea during the 1990s
(Lavender et al., 2000). In line with this view is a further upwelling event in 1983-1984. It was accompanied by a minor increase of juvenile redfish, in particular at East Greenland in 1985. Since summer plankton productivity was low then in July-August, probably no larger population could be maintained.

In this analysis, effects of fisheries was assigned directly to $12.9 \%$ of community variability, i.e. prin 3 , and indirectly to prin 2 accounting for $16.7 \%$ of variability. This pattern is associated to juvenile redfish, golden redfish, cod, and American plaice. In cod fisheries, heavy discards of juvenile redfish have been described in the past (Pedersen and Rice, 2002). Thus, the cod fisheries are likely to have had an overall effect. The approach is justified by the congruence between time series of abundance index of cod at age 3 according to Myers et al. 
TABLE 7. Moving-window correlations by pentade and interpretation of resulting patterns as driving forces for East Greenland. Values including summer survey 1981 in parentheses. ple-prin1 east, chl78 - PCI for July and August, nuuk - Nuuk ATA, $F$ - fishing mortality.

\begin{tabular}{|c|c|c|c|c|c|c|c|}
\hline Pentade & Driving force & ple-nuuk & p2e-chl78 & p2e-F & p3e-chl78 & $\mathrm{p} 3 \mathrm{e}-\mathrm{F}$ & p4e-nuuk \\
\hline 1981-1985 & & $(0.6)$ & $(-0.9)$ & $(0.4)$ & $\left(0.78^{*}\right)$ & $(-0.8)$ & $(0.3)$ \\
\hline 1982-1986 & \multirow{6}{*}{$\begin{array}{l}\text { Fisheries } \\
\text { and } \\
\text { climate }\end{array}$} & $0.90^{*}$ & -0.4 & -0.5 & 0.3 & -0.3 & 0.3 \\
\hline 1983-1987 & & $0.89^{*}$ & & -0.1 & & 0.4 & 0.4 \\
\hline 1984-1988 & & $0.87^{*}$ & & 0.6 & & $-0.82 *$ & 0.3 \\
\hline 1985-1989 & & 0.6 & & $0.76^{*}$ & & $-0.76^{*}$ & 0.7 \\
\hline 1986-1990 & & $0.80^{*}$ & & $0.76^{*}$ & & $-0.81 *$ & 0.6 \\
\hline 1987-1991 & & $0.93^{*}$ & & $0.90 *$ & & -0.2 & 0.7 \\
\hline 1988-1992 & & 0.3 & & 0.7 & & 0.6 & 0.7 \\
\hline 1989-1993 & & -0.9 & & & & & 0.3 \\
\hline 1990-1994 & & 0.0 & & & & & 0.7 \\
\hline 1991-1995 & \multirow{7}{*}{$\begin{array}{c}\text { Productivity } \\
\text { and } \\
\text { climate }\end{array}$} & -0.2 & -0.2 & & $0.95^{*}$ & & 0.5 \\
\hline 1992-1996 & & 0.3 & -0.1 & & $0.92 *$ & & 0.6 \\
\hline 1993-1997 & & $0.74^{*}$ & -0.1 & & $0.92 *$ & & 0.5 \\
\hline 1994-1998 & & 0.5 & 0.1 & & 0.6 & & 0.1 \\
\hline 1995-1999 & & $1.00 *$ & -0.8 & & 0.0 & & -0.1 \\
\hline 1996-2000 & & 0.3 & $0.76^{*}$ & & $0.87^{*}$ & & -0.2 \\
\hline 1997-2001 & & 0.5 & $0.75^{*}$ & & $0.87 *$ & & 0.2 \\
\hline 1998-2002 & & 0.6 & & & & & 0.7 \\
\hline 1999-2003 & \multirow{3}{*}{ Climate } & 0.7 & & & & & $0.94 *$ \\
\hline 2000-2004 & & $0.98^{*}$ & & & & & $0.98^{*}$ \\
\hline 2001-2005 & & $0.94 *$ & & & & & $0.95^{*}$ \\
\hline 2002-2006 & & 0.6 & & & & & 0.7 \\
\hline
\end{tabular}

(1997) and fishing mortality (Fig. 6). The index shows that mortality was underrated by VPA. Myers et al. (1997) attribute this numerical pattern to increased fishing mortality, in particular discard mortality and underreporting of catches when fishing effort is high.

\section{Community interactions and regional differences}

The analysis revealed a clear separation between West and East Greenland assemblages. This supports the analysis by Rätz (1999) indicating differences in community structure between East and West Greenland. Phase diagrams showed positive relationships for East Greenland, but negative for West Greenland. One strong cyclic pattern appeared. Cycles can be regarded as transitional regime shifts, always associated with certain changes in biological features, e.g. reduction of trophic level, etc. (Beaugrand and Ibanez, 2004; Poulard and Blanchard, 2005). For prin1-prin2, the shift can be identified as ontogenetic cycle from juvenile to larger redfish with presumably changing ecological requirements between both states. The relationship is positive, with high loads in the juveniles leading to high loads in adult redfish. The survey data supports this interpretation indicating an increase for deep-sea redfish in 1996-97 and an increase for golden redfish 1998 and since 2001. Further, for the Irminger Sea strong recruitment from the shelf to the offshore pelagic stock was observed in the late 1990s (Stransky, MS 2000).

The negative phase relationships for West Greenland indicate community, i.e. competitive interactions between cod, American plaice and redfish. In particular, golden redfish is negatively correlated with prin4 and cod with prin1. Competition requires some limiting resource. Sea temperature profiling during the 1984-cruise indicates that warmer water is distributed over most of 
the East Greenland shelf, whereas warm water in West Greenland occurs deeper and is bound to the shelf edge (Stein, MS 2006b). The distribution of prin1 in West Greenland confined to the outer margins of the survey area where warmer water appears indicates that warmer water could be the limiting resource quality. Survey data from the Aleutian Chain show a likely corroborating pattern between Pacific cod (G. macrocephalus) and Pacific ocean perch (Sebastodes alutus) (Logerwell et al., 2005). On the northern side, i.e. the colder side as evidenced by measurements from temperature moorings (Stabeno et al., 2005), spatial overlap between perch and cod was stronger than on the southern side. Negative relationships can be caused either by means of diet overlap, since shrimp are a common resource to all demersal fishes, but more directly through predation of one species on the other. Cod is a heavy predator on golden redfish, but redfish also feed on juvenile cod and American plaice (Roman et al., MS 2004; Savenkoff et al., MS 2006). Thus, in a limited environment cod could hinder the establishment of the redfish stock, and vice versa. This process would be performed as an ecological shift or cycle and is density dependent.

As a consequence, in East Greenland where apparently warm water is not a limiting resource the relationship should be bottom-up controlled, i.e. density independent. This is strongly supported by the moving window correlation patterns. For West Greenland, significant correlations were limited to certain periods with temporal gaps between them, leaving space for density dependent regulation. Such switching between density dependent and density independent regulation was also found for East Pacific sardines (Kawasaki and Omori, 1995). In turn, in East Greenland significant moving window correlations appeared for the whole period, indicating strong bottom-up forcing. Knowledge of density independent forcing may have certain implications for management (Brander and Mohn, 2004).

\section{References}

ABOOKIRE, A. A., J. F. PIATT, and M. D. ROBARDS. 2000. Nearshore fish distributions in an Alaskan estuary in relation to stratification, temperature and salinity. Estuar. Coast. Shelf Sci., 51: 45-59. doi:10.1006/ecss.1999.0615

ANDERSON, P. J. 2000. Pandalid shrimp as indicators of ecosystem regime shift. J. Northw. Atl. Fish. Sci., 27: 1-10.

ANDERSON, P. J., and J. F. PIATT. 1999. Community reorganization in the Gulf of Alaska following ocean climate regime shift. Mar. Ecol. Prog. Ser., 189: 117-123.

ATTRILL, M. J., and M. POWER. 2002. Climatic influence on a marine fish assemblage. Nature, 417: 275-278. doi: $10.1038 / 417275 \mathrm{a}$
BACKHAUS, K., B. ERICHSON, W. PLINKE, and R. WEIBER. 1990. Multivariate Analysemethoden - Eine anwendungsorientierte Einführung. Springer, Berlin.

BEAUGRAND, G., K. BRANDER, J. A. LINDLEY, S. SOUISSI, and P. C. REID. 2003. Plankton effect on cod recruitment in the North Sea. Nature, 426: 661-664. doi: 10.1038 /nature 02164

BEAUGRAND, G., and F. IBANEZ. 2004. Monitoring marine plankton ecosystems. II: Long-term changes in North Sea calanoid copepods in relation to hydro-climatic variability. Mar. Ecol. Prog. Ser., 284: 35-47.

BRANDER, K. M. 1996. Effects of climate change on cod (Gadus morhua) stocks. In: Global warming: Implications for freshwater and marine fish. C. M. Wood, and D. G. McDonald (eds.). Cambridge University Press, Cambridge, p. 255-278.

2005. Cod recruitment is strongly affected by climate when stock biomass is low. ICES J. Mar. Sci., 62: 339-343. doi:10.1016/j.icesjms.2004.07.029

BRANDER, K. M., and R. MOHN. 2004. Effect of the North Atlantic Oscillation on recruitment of Atlantic cod ( $\mathrm{Ga}$ dus morhua). Can. J. Fish. Aquat. Sci., 61: 1558-1564. doi:10.1139/f04-087

BUCH, E., and M. H. NIELSEN. MS 2002. Oceanographic investigations off West Greenland 2001. NAFO SCR Doc., No. 17, N4618, 14 p.

BUCH E., M. H. NIELSEN, and S. A. PEDERSEN. 2003. On the coupling between climate, hydrography and recruitment variability of fishery resources off West Greenland. ICES J. Mar. Sci., 219: 231-240.

BUCH, E., S. A. PEDERSEN, and M. H. RIBERGAARD. 2004. Ecosystem variability in West Greenland waters. J. Northw. Atl. Fish. Sci., 34: 13-28. doi:10.2960/J.v34. $\mathrm{m} 479$

CATTELL, R. B. 1966. The scree test for the number of factors. Multivariate Behavioural Research, 1: 629-637. doi:10.1207/s15327906mbr0102 10

DELWORTH, T. L., S. MANABE, and R. J. STOUFFER. 1997. Multidecadal climate variability in the Greenland Sea and surrounding regions: A coupled model simulation. Geophys. Res. Lett. 24: 257-260. doi:10.1029/96GL03927

DINIZ-FILHO, J. A. F., L. M. BINI, and B. A. HAWKINS. 2003. Spatial autocorrelation and red herrings in geographical ecology. Global Ecol. Biogeogr., 12: 53-64. doi:10.1046/j.1466-822X.2003.00322.x

FOCK, H., and W. GREVE. 2002. Analysis and interpretation of recurrent spatio-temporal patterns in zooplankton dynamics: a case study on Noctiluca scintillans (Dinophyceae) in the German Bight (North Sea). Mar. Biol., 140: 59-73. doi:10.1007/s002270100685

FRANCIS, R. C., R. HARE S., A. B. HOLLOWED., and W. S. WOOSTER. 1998. Effects of interdecadal climate variability on the oceanic ecosystems of the NE Pacific. Fish. Oceanogr., 7: 1-21. doi:10.1046/j.13652419.1998.00052.x

GENNER, M. J., D. W. SIMS, V. WEARMOUTH, E. J. SOUTHALL, A. J. SOUTHWARD, P. A. HENDERSON, and S. J.HAWKINS. 2004. Regional climatic warming 
drives long-term community changes of British marine fish. Proc. R. Soc. Lond. (B Biol. Sci.), 271: 655-661. doi:10.1098/rspb.2003.2651

HAMILTON, L. C., B. C. BROWN, and R. O. RASMUSSEN. 2003. West Greenland's cod-to-shrimp transition: Local dimensions of climate change. Arctic, 56: 271-282.

HEYEN, H., H. FOCK, and W. GREVE. 1998. Detecting relationships between the interannual variability in ecological timeseries and climate using a multivariate statistical approach - a case study for Helgoland Roads zooplankton. Clim. Res., 10: 179-191.

ICES. MS 1996. Report of the North Western Working Group, May 1-8, 1996. ICES CM 1996/Assess:15, ICES Headquarters, $377 \mathrm{p}$.

MS 2006. Report of the North-Western Working Group (NWWG), 25 April-4 May 2006. ICES CM 2006/ ACFM:26, ICES Headquarters, 604 p.

KAISER, H. F. 1960. The application of electronic computers to factor analysis. Educational and Psychological Measurement, 20: 141-151. doi:10.1177/0013164460020001 16

KAWASAKI, T., and M. OMORI. 1995. Possible mechanisms underlying fluctuations in the Far Eastern sardine population inferred from time series of two biological traits. Fish. Oceanogr., 4: 238-242.

LAVENDER, K. L., R. E. DAVIS, and W. B. OWENS. 2000. Mid-depth recirculation observed in the interior Labrador and Irminger seas by direct velocity measurements. $\mathrm{Na}$ ture, 407: 66-69. doi:10.1038/35024048

LEHOUDEY, P., J. AHLHEIT, M. BARRANGE, T. BAUMGARTNER, G. BEAUGRAND, K. DRINKWATER, J. M. FROMENTIN, S. R. HARE, G. OTTERSEN, R. I. PERRY, C. ROY, C. D. VAN DER LINGEN, and F. WERNER. 2006. Climate variability, fish and fisheries. $J$. Clim., 19: 5009-5030. doi:10.1175/JCLI3898.1

LOGERWELL, E. A., K. AYDIN, S. BARBEAUX, E. BROWN, M. E. CONNERS, S. LOWE, J. W. ORR, I. ORTIZ, R. REUTER, and P. SPENCER. 2005. Geographic patterns in the demersal ichthyofauna of the Aleutian Islands. Fish. Oceanogr., 14: 93-112.

MACDONALD, J. S., M. J. DADSWELL, R. G. APPLY, G. D. MELVIN, and D. A. METHVEN. 1984. Fishes, fish assemblages, and their seasonal movements in the Lower Bay of Fundy and Passamaquoddy Bay, Canada. Fish. Bull., 82: 121-139.

MAGILL, S. H., and M. D. J. SAYER. 2002. Seasonal and interannual variation in fish assemblages of northern temperate rocky subtidal habitats. J. Fish Biol., 61: 11981216. doi:10.1111/j.1095-8649.2002.tb02465.x

MAUNDER, M. N., J. R. SIBERT, A. FONTENEAU, J. HAMPTON, P. KLEIBER, and S. J. HARLEY. 2006. Interpreting catch per unit effort data to assess the status of individual stocks and communities. ICES J. Mar. Sci., 63: 1373-1385. doi:10.1016/j.icesjms.2006.05.008

MEEHL, G. A., and VAN LOON, H. 1979. The seesaw in winter temperatures between Greenland and Northern Europe. Part III: Teleconnections with Lower Latitudes. Monthly Weather Review, 107: 1095-1106. doi:10.1175/15200493(1979)107<1095:TSIWTB >2.0.CO;2
MYERS, R. A., J. A. HUTCHINGS, and N. J. BARROWMAN. 1997. Why do fish stocks collapse? The example of cod in Atlantic Canada. Ecol. Appl., 7: 91-106. doi: $10.2307 / 2269409$

OGI, M., Y. TACHIBANA, and K.YAMAZAKI. 2004. The Connectivity of the Winter North Atlantic Oscillation (NAO) and the Summer Okhotsk High. J. Meteorol. Soc. Japan, 82: 905-913. doi:10.2151/jmsj.2004.905

PARMESAN, C., and G.YOHE. 2003. A globally coherent fingerprint of climate change impacts across natural systems. Nature, 421: 37-42. doi:10.1038/nature01286

PEDCHENKO, A. P. 2005. The role of interannual environmental variations in the geographic range of spawning and feeding concentrations of redfish Sebastes mentella in the Irminger Sea. ICES J. Mar. Sci., 62: 1501-1510. doi:10.1016/j.icesjms.2005.08.004

PEDERSEN, S. A., and J. C. RICE. 2002. Dynamics of fish larvae, zooplankton, and hydrographical characteristics in the West Greenland large marine ecosystem 1950-1984. In: Large Marine Ecosystems of the North Atlantic Changing States and Sustainability. K. Sherman, and H.R. Skjoldal. (eds.). Elsevier, Amsterdam, p. 151-193.

PERRY, A. L., P. J. LOW, J. R. ELLIS, and J. D. REYNOLDS. 2005. Climate change and distribution shifts in marine fishes. Science, 308: 1912-1915. doi:10.1126/science. 1111322

POULARD, J.-C., and F. BLANCHARD. 2005. The impact of climate change on the fish community structure of the eastern continental shelf of the Bay of Biscay. ICES J. Mar. Sci., 62: 1436-1443. doi:10.1016/j.icesjms.2005.04.017

RÄTZ, H.-J. 1999. Structures and changes of the demersal fish assemblage off Greenland, 1982-1996. NAFO Sci. Council. Stud. , 32: 1-15.

RICHARDSON, A. J., A. W. WALNE, A. W. G. JOHN, T. D. JONAS, J. A. LINDLEY, D. W. SIMS, D. STEVENS, and M. WITT. 2006. Using continous plankton recorder data. Prog. Oceanog., 8: 27-74. doi:10.1016/ j.pocean.2005.09.011

ROMAN, E., C. GONZALEZ, and E. CEBALLOS. MS 2004. Food and Feeding of Most Abundant Fish Species in Flemish Cap. NAFO SCR Doc., No. 58, Serial No. N5018, $17 \mathrm{p}$.

ROSE, G. A. 2004. Reconciling overfishing and climate change with stock dynamics of Atlantic cod (Gadus morhua) over 500 years. Can. J. Fish. Aquat. Sci., 61: 1553-1557. doi:10.1139/f04-173

SABORIDO-REY, F., D. GARABANA, C. STRANSKY, S. MELNIKOV, and V.SHIBANOV. 2004. Review of the population structure and ecology of $S$. mentella in the Irminger sea and adjacent waters. Rev. Fish Biol. Fish., 14: 455-479. doi:10.1007/s11160-005-3585-9

SAHFOS. 2006. The CPR Survey. http://192.171.163.165/ standard areas.htm

SAS. 2003. SAS/STAT User's Guide, Version 9. SAS Institute Inc., Cary, NC.

SAVENKOFF, C., B. MORIN, D. CHABOT, and M. CASTONGUAY. MS 2006. Main prey and predators of redfish (Sebastes spp.) in the northern Gulf of St. Lawrence during the mid-1980s, mid-1990s and early 2000s. Report 
No. 2648, Direction des Sciences eches, Mont-Joli.

SCHEFFER, M., S. CARPENTER, J. A. FOLEY, C. FOLKE, and B. WALKER. 2001. Catastrophic shifts in ecosystems. Nature, 413: 591-596. doi:10.1038/35098000

SCHWING, F. B., J. JIANG, R. MENDELSSOHN. 2003. Coherency of multi-scale abrupt changes between the NAO, NPI, and PDO. Geophys. Res. Lett., 30: 591-594. doi:10.1029/2002GL016535

SIRABBELLA, P., A. GIULIANI, A. COLOSIMO, and J. W.DIPPNER. 2001. Breaking down the climate effects on cod recruitment by principal component analysis and canonical correlation. Mar. Ecol. Prog. Ser., 216: 213-222.

STABENO, P. J., D. G. KACHEL, N. B. KACHEL, and M. E. SULLIVAN. 2005. Observations from moorings in the Aleutian Passes: temperature, salinity and transport. Fish. Oceanogr., 14: 39-54. doi:10.1111/j.13652419.2005.00362.x

STAHEL, W. A. 1999. Statistische Datenanalyse. Vieweg, Braunschweig.

STEBBING, A. R. D., S. M. T. TURK, A. WHEELER, and K. R. CLARKE. 2002. Immigration of southern fish species to south-west England Linked to warming of the North Atlantic. J. Mar. Biol. Assoc. U.K., 82: 177-180. doi: $10.1017 / \mathrm{S} 0025315402005325$

STEELE, J. H. 1998. From carbon flux to regime shift. Fish. Oceanogr., 7: 176-181. doi:10.1046/j.13652419.1998.00069.x

STEIN, M. 2004. Climatic Overview of NAFO Subarea 1, 1991-2000. J. Northw. Atl. Fish. Sci., 34: 29-40. doi:10.2960/J.v34.m474

2006a. North Atlantic Subpolar Gyre Warming - Impacts on Greenland Offshore waters. J. Northw. Atl. Fish.
Sci., 36: 43-54. doi:10.2960/J.v36.m568

MS 2006b. Oceanographic conditions off East and West Greenland - based on the CTD measurements during the 1984 cruise of FRV "Walther Herwig II". http://www. klima-bml.de/wh067

STEIN, M., and V. A. BOROVKOV. 2004. Greenland cod (Gadus morhua): modeling recruitment variation during the second half of the 20th century. Fish. Oceanogr., 13: 111-120. doi:10.1046/j.1365-2419.2003.00280.x

STEIN, M., and J. LLORET. 1995. Stability of water masses - impact on cod recruitment off West Greenland. Fish. Oceanogr., 4: 230-237.

STEINGRUND, P., and E. GAARD. 2005. Relationship between phytoplankton production and cod production on the Faroe Shelf. ICES J. Mar. Sci., 62: 163-172. doi:10.1016/j.icesjms.2004.08.019

STRANSKY, C. MS 2000. Migration of juvenile deep-sea redfish (Sebastes mentella Travin) from the East Greenland shelf into the central Irminger Sea. ICES CM 2000/ $\mathrm{N}: 28,10 \mathrm{p}$.

URQUHART, N. S., S. G. PAULSEN, and D. P. LARSEN. 1998. Monitoring for policy-relevant regional trends over time. Ecol. Appl., 8: 246-257. doi:10.2307/2641064

WALTHER, G.-R., E. POST, P. CONVEY, A. MENZEL, C. PARMESAN, J. C. BEEBEE T., J.-M. FROMENTIN, O. HOEGH-GULDBERG, and F. BAIRLEIN. 2002. Ecological responses to recent climate change. Nature, 416: 389-395. doi:10.1038/416389a

WARE, D. M., and R. E. THOMSON. 2005. Bottom-up ecosystem trophic dynamics determine fish production in the Northeast Pacific. Science, 308: 1280-1284 doi:10.1126/ science. 1109049 